\title{
Driving Risk Affected Areas and Distribution Function of Sharp Horizontal Curves of Expressway
}

\author{
Xiao-fei Wang, ${ }^{1}$ Xin-wei Li, ${ }^{1}$ Ying Yan, ${ }^{2}$ and Xin-sha Fu ${ }^{1}$ \\ ${ }^{1}$ School of Civil Engineering and Transportation, South China University of Technology, Guangzhou 510640, China \\ ${ }^{2}$ Key Laboratory of Automobile Transportation Safety Support Technology, Chang'an University, Xian 710064, China \\ Correspondence should be addressed to Xiao-fei Wang; xiaofeiw@scut.edu.cn
}

Received 16 July 2014; Accepted 25 August 2014

Academic Editor: Heiner Bubb

Copyright (c) 2015 Xiao-fei Wang et al. This is an open access article distributed under the Creative Commons Attribution License, which permits unrestricted use, distribution, and reproduction in any medium, provided the original work is properly cited.

\begin{abstract}
The average death and injury intensity on sharp horizontal curves (SHCs) are much higher than those of straight sections of the expressway in China. In this paper, the statistics of crashes from 2008 to 2012 on $2200 \mathrm{~km}$ expressways in Guangdong province are collected, and the relationships between the radius of plane curves and the crash rate are analyzed. After that, the curved expressway section with radius equal to or less than $1000 \mathrm{~m}$ is defined as SHCs. According to the results of the test of the operating speed, the heart rate change of drivers, and the vehicle acceleration, the distribution patterns of driving risks on the certain SHCs were theoretically analyzed. Hence, the driving risk affected areas on adjacent line units of SHCs are determined as $200 \mathrm{~m}$ sections before entering or after exiting the SHCs. Combining with surveyed data, the spatial distribution of crashes on SHCs is analyzed, and the driving risk distribution function of SHCs in expressway is finally deduced. The result of this research provides a theoretical basis to enhance expressway safety management and to improve the driving safety on SHCs.
\end{abstract}

\section{Instruction}

Kanellaidis and Vardaki [1] believe that highway geometric design is the essential issue of highway safety. Earlier researches show that horizontal curve position, radius, and easement curve have a remarkable relationship with crashes [2]. SHCs are widely used in expressway in the mountainous areas. According to Traffic Accidents Statistics Yearbook of People's Republic of China (from 2001 to 2012) [3], during the last 10 years, statistics show that the average death and injury intensity of SHCs are 33.08 persons per 100 crashes (P\%) and $113.90 \mathrm{P} \%$, but the average death and injury intensity of straight sections of highway are $18 \mathrm{P} \%$ and $74.86 \mathrm{P} \%$ in the same period of time, which shows that the crash severity of SHCs is much higher than that of straight sections of highway in China. Thus, safety improvements of SHCs are eager to be done to reduce the harm of SHCs crashes.

Based on crashes data of $2200 \mathrm{~km}$ expressways collected in Guangdong from 2008 to 2012, SHCs are firstly defined according to the relationship between radius and crashes ratio; then driving risk distribution and affected areas on adjacent line units are theoretically analyzed according to the testing results of operating speed, heart rate variability of driver, and acceleration changes when driving on SHCs. Combined with survey and research data, spatial distribution of crashes in SHCs is analyzed, and driving risk distribution function of SHCs in expressway is further deduced which provides theoretical basis to enhance expressway safety management and improve driving safety of SHCs.

\section{Definition of SHC}

By analyzing crash data of expressway plane curves in Guangdong, the relationship (crash number in $10^{6}$ vehicle kilometers traveled) between the crash frequency and radius is shown in Figure 1.

The result shows that there is typical power function relation between crash frequency and radius of expressway plane curves and crash frequency is obviously lower with larger radius of plane curves. The curve also shows that when radius is less than $1000 \mathrm{~m}$, crash frequency changes remarkably. On the contrary, changing magnitude of crash frequency is significantly lower when radius is more than $1000 \mathrm{~m}$. Characteristic point of the curves is just on $1000 \mathrm{~m}$ 


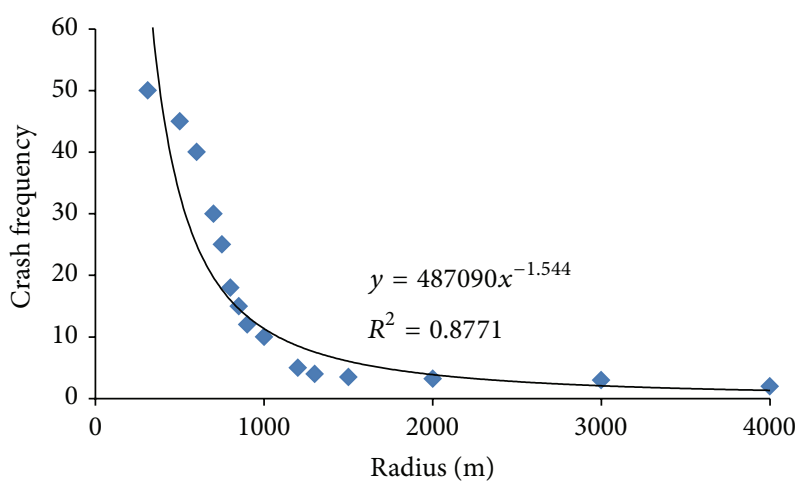

FIGURE 1: Relationship between crash frequency and radius of expressway plane curves.

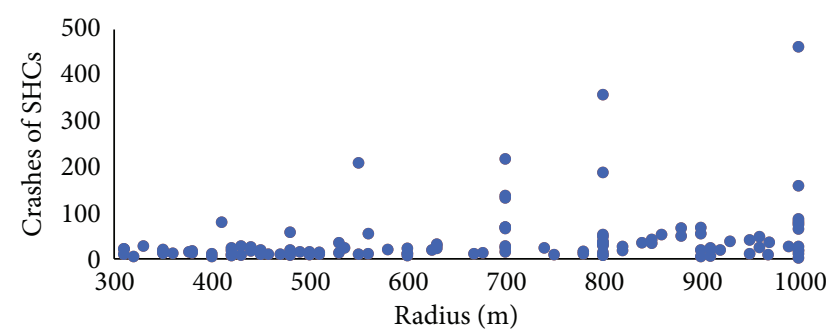

FIgURE 2: Crashes of 117 SHCs in survey data (Guangdong, 20082012).

radius. Thus, the $\mathrm{SHC}$ is defined as radius less than or equal to $1000 \mathrm{~m}$ in this paper.

According to the definition, 117 SHCs and 4726 crashes (showed in Figure 2) are screened out from survey data during 2008 and 2012 in Guangdong province.

\section{The Driving Risk Spatial Distribution Rule of SHCs}

Firstly, driving risk distribution is theoretically analyzed by testing results of indirect index, such as operating speed of vehicles, heart rate variability of driver, and acceleration changes when driving on SHCs. Then combined theoretical analysis with statistical analysis of survey data and consistency between theoretical and actual results are verified in the paper.

\subsection{Driving Risk Distribution and Affected Areas of SHC}

3.1.1. Operating Speed. An operating speed test is conducted on SHCs in accordance with the study of crash frequency and velocity dispersion. The results $[4,5]$ show that the operating speed of the drivers is not constant on the curved segment. The velocity of the vehicles when they are leaving the curves was about $6.4-8 \mathrm{~km} / \mathrm{h}[6]$ higher than when they are entering the curves. The operating speed of the vehicles varies before and after they pass the midpoint of the circular curve. The rapid change of operating speed of the vehicles driving on SHCs easily leads to potential traffic safety problems and keenly increases the driving risk [7-9]. The results also

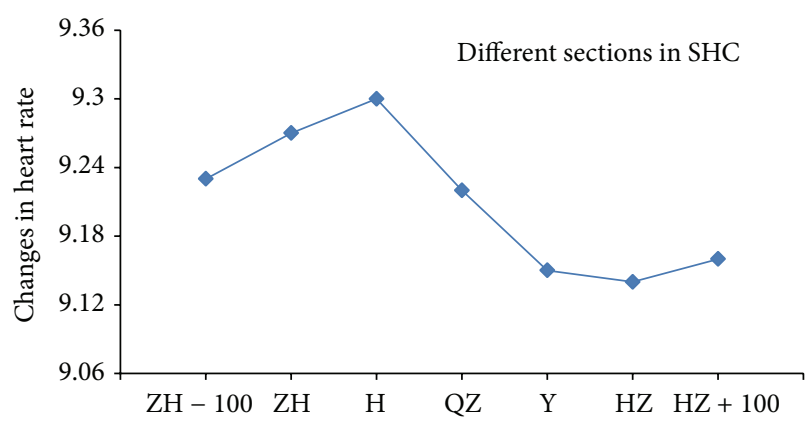

Figure 3: Changes in heart rate of experienced driver passing different sections in SHC. ZH: point of tangent to spiral, $\mathrm{ZH}-100$ : $100 \mathrm{~m}$ before $\mathrm{ZH}, \mathrm{HZ}$ : point of spiral to tangent, $\mathrm{HZ}+100: 100 \mathrm{~m}$ after HZ, H: point of spiral to circle, Y: point of circle to spiral, and QZ: middle point of circle.

illustrate that the pattern of operating speed is frequently in deceleration when entering the SHCs, while usually in acceleration when leaving it. The discrete speed distribution leads to the rapid increase of driving risks.

3.1.2. Changes in Heart Rate of Drivers. Heart rate is another important indicator used to measure people's psychological and physiological load, which is proportional to the intensity of their operations and the tension level of driver. For drivers, the high physiological load can predispose people to mental fatigue, stress, resulting in erroneous driving behavior which might greatly affect traffic safety. JORNA's studies show that $20 \%$ more than normal heart rate may cause driver nervousness and 40\% more may cause emerging affright [10].

Studies of drivers' psychological and physiological characteristics changes indirectly reflected the distribution of driving risk driving along SHCs. The testing results of changes in heart rate of experienced driver passing different sections in SHC are shown in Figure 3.

The testing result shows that the heart rate of driver is firstly increased and gradually decreased with adapting to changes of line and increased again for accelerating to exit curve, when driving along SHC.

3.1.3. Acceleration Changes. The measurement results [11] of longitudinal acceleration of motor coach through SHC with speed of $30 \mathrm{~km} / \mathrm{h}, 40 \mathrm{~km} / \mathrm{h}$, and $50 \mathrm{~km} / \mathrm{h}$ were shown in Figure 4.

The test results showed that vehicle was frequently decelerated and deceleration value was maximum just before entering SHC. After passing the point of tangent to spiral, vehicle still remained decelerating with more braking frequency than that in straight line before curve, and the mean deceleration value slightly fluctuated with little changes. Around curve midpoint, vehicle's acceleration was close to 0 . Through curve midpoint, vehicle was gradually accelerated, and the average acceleration is gradually increased.

According to the changes of vehicle acceleration in SHCs, the driving risk distribution can be described in which risk values are increased for frequent deceleration before entering 


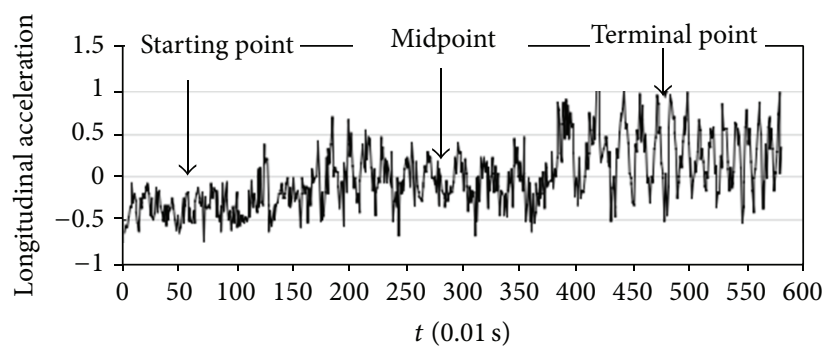

(a) $30 \mathrm{~km} / \mathrm{h}$

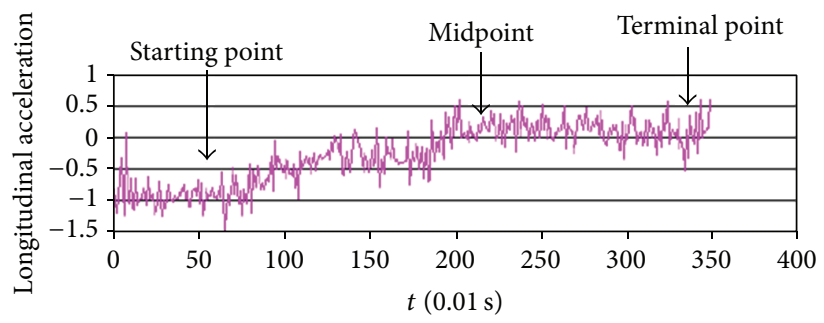

(b) $40 \mathrm{~km} / \mathrm{h}$

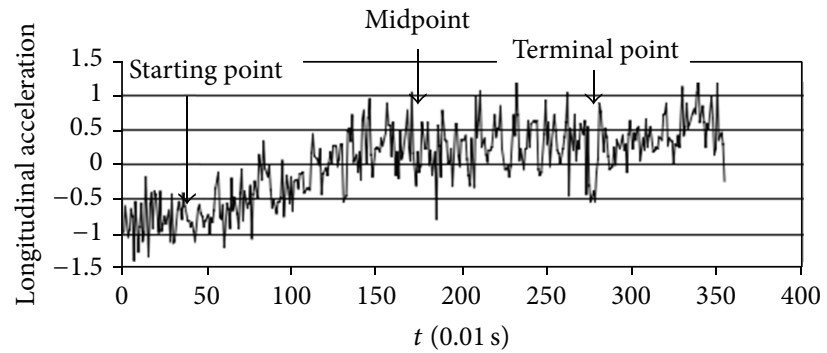

(c) $50 \mathrm{~km} / \mathrm{h}$

FIGURE 4: Longitudinal acceleration distribution of motor coach with different speed passing SHC.

the curve. Risk values of vehicle driving in the curve are increased to maximum for much more frequent deceleration to gradually adapt to the curvature changes. Risk begins to decrease when vehicle begins to accelerate and the decrease stops just at the end of SHC.

3.2. Driving Risk Affected Areas of SHC. Based on the above analysis, most predecelerating and accelerating sections of SHCs are located in adjacent segment units [12]. Therefore, determination of affected areas on adjacent units is important to calibrate driving risk distribution function and divide segments for establishing prediction models. With the measurement results of characteristic operating speeds and changes of drivers' heart rate, the affected areas on adjacent units before SHCs can be calculated, and the affected areas after SHCs can also be analyzed by the acceleration of vehicles.

\subsubsection{Affected Areas before SHCs}

Measurement Results of Characteristic Operating Speeds. Testing results [11] of characteristic operating speeds, such as radius of SHCs, deceleration point, speed on deceleration point, are shown in Table 1.
The results show that predecelerating lengths which substantially concentrate in about $200 \mathrm{~m}$ are inconsistent with different radius and speed on deceleration point.

Changes of Drivers' Heart Rate. The drivers' average instantaneous changes of heart rate with occurrence position and operating speed are measured before entering SHCs, and the testing results [13] are shown in Table 2.

Test results show that driver's heart rate greatly changed before entering SHC and the changing position is located at about $200 \mathrm{~m}$ before SHC.

Length of Affected Areas. According to testing results of operating speeds and changes of heart rate, the length for deceleration is about $200 \mathrm{~m}$ before SHC. So the length of affected areas before SHC is determined as $200 \mathrm{~m}$.

Affected Areas after Exiting SHC. Considering dual directional traffic of expressway, the starting point is the end of another direction, and vehicles with lower risk are always accelerated after exiting SHC. Based on above analysis and length of affected areas before entering, the length after exiting is also defined as $200 \mathrm{~m}$. 
TABLE 1: Testing results when vehicles are driving along SHCs.

\begin{tabular}{|c|c|c|c|c|c|c|c|c|c|c|c|c|}
\hline Radius (m) & 200 & 350 & 400 & 450 & 470 & 500 & 550 & 600 & 665 & 700 & 750 & 800 \\
\hline Speed on deceleration point $(\mathrm{km} / \mathrm{h})$ & 109 & 123.5 & 111.5 & 113.3 & 113.3 & 123.3 & 117 & 123 & 120.5 & 126.7 & 124.9 & 118.7 \\
\hline Predeceleration length $(\mathrm{m})$ & 197 & 251 & 170 & 170 & 167 & 210 & 168 & 186 & 165 & 185 & 169 & 123 \\
\hline
\end{tabular}

TABLE 2: Drivers' instantaneous changes of heart rate, occurrence position, and operating speed before entering SHCs.

\begin{tabular}{lcccc}
\hline Radius $(\mathrm{m})$ & $\begin{array}{c}\text { Average instantaneous } \\
\text { changes of heart rate (\%) }\end{array}$ & $\begin{array}{c}\text { Travel time before entering } \\
\text { SHCs }(\mathrm{s})\end{array}$ & $\begin{array}{c}\text { Average operating speed } \\
(\mathrm{km} / \mathrm{hr})\end{array}$ & $\begin{array}{c}\text { Distances to point of } \\
\text { tangent to spiral }(\mathrm{m})\end{array}$ \\
\hline $200 \sim 600$ & 28.83 & 3.17 & 96 & 74.05 \\
$600 \sim 1000$ & 28.26 & 3.31 & 100 & 85.51 \\
More than 1000 & 21.89 & 7.06 & 101 & 197.15 \\
\hline
\end{tabular}

3.3. Crashes Distribution of Survey Data of SHCs. To analyze the crash distribution of SHCs with different lengths, normalization processing of crash data is carried out, so basic variables are converted into the proportion of the crashes of subsections to that of total section. The analysis results are shown in Table 3.

Driving along SHCs, the risk of vehicles begins to increase in the range about $200 \mathrm{~m}$ before entering curves. After entering the 1st spiral curve, driving risk increases gradually with the changing curvature. In spiral curve or circular curve around point of spiral to circle, the driving risk value is the highest and then gradually reduces until exiting the 2nd spiral curve. Entering affected area after exiting SHC, the risk remains at low level.

\section{Driving Risk Distribution Function of SHCs}

In summary, crashes spatial distribution and analysis results of affected areas show that operating speed, heart rate, and acceleration along travel direction are changing with similar rule, and driving risk distribution is not even. Driving risk increases gradually in deceleration section before entering curves and reaches the highest value at the point of spiral to circle. Then gradually risk decreases after passing half curve. With analysis of these indirect indexes, distribution function form of driving risk of SHCs can be assumed.

4.1. Distribution Function Form. According to the changing regulations of drivers' heart rate and operating speed, driving risk distribution can be described as cubic polynomial listed as follows:

$$
y=e^{\left(a x^{3}+b x^{2}+c x+d\right)}
$$

where $a, b, c$, and $d$ are the estimated parameters; $y$ is the driving risk parameter driving along curves; $x$ is the position of the vehicle on the curve.

For the convenience of calculation, formula (1) is converted into formula (2) by natural logarithm:

$$
\ln y=a x^{3}+b x^{2}+c x+d
$$

where $a, b, c$, and $d$ are the estimated parameters.

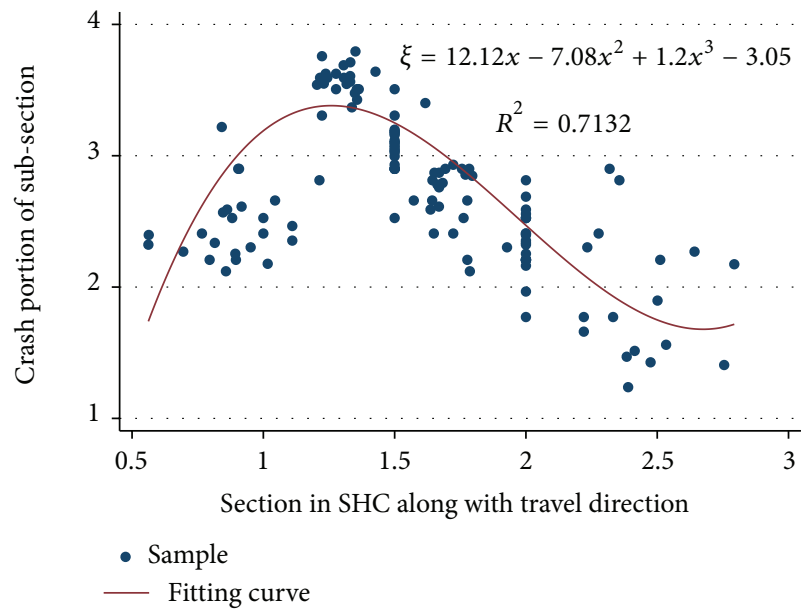

FIGURE 5: Driving risk distribution of SHCs along with travel direction.

4.2. Parameter Calibration. To avoid abscissa values of affected areas less than 0,1 is assigned to the value of point of tangent to spiral, and the values of different sections can be calculated. The driving risk distribution is shown in Figure 5.

Estimated parameters in formula (2) can be calibrated by survey crashes in SHCs, and the expression of driving risk distribution function is shown in the following formula:

$$
\begin{gathered}
\phi=e^{\left(12.12 x-7.08 x^{2}+1.2 x^{3}-3.1\right)} \\
=0.045 e^{\left(12.12 x-7.08 x^{2}+1.2 x^{3}\right)}, \\
x=\frac{\sum_{i=1}^{6} l_{i}}{L},
\end{gathered}
$$

where $L$ is the length of analysis area of SHCs and $L=200+$ $l+200, l$ is the length of SHC, $l_{i}$ is the length of subsection $i$, and $i$ is the number of subsections, $i=1,2, \ldots, 6$.

\section{Conclusion}

SHCs are one of the traffic accident prone locations in expressways. The paper has surveyed a large sum of data and quoted a great deal of references to reveal and prove driving 
TABLE 3: Normalization processing results of crashes of SHCs.

\begin{tabular}{lcccc}
\hline Category & Mean (\%) & Standard deviation & Minimum value (\%) & Maximum value (\%) \\
\hline Total & 16 & 10.46 & 0 & 44.44 \\
Subsection 1 (affected area before entering SHC) & 12.23 & 3.83 & 8.33 & 25.32 \\
Subsection 2 (1st spiral curve) & 34.89 & 5.67 & 16.67 & 44.44 \\
Subsection 3 (1st 1/2 circular curve) & 21.38 & 4.24 & 12.5 & 3.33 \\
Subsection 4 (2nd 1/2 circular curve) & 15.47 & 4.48 & 5.88 & 30 \\
Subsection 5 (2nd spiral curve) & 10.70 & 2.42 & 0 & 16.67 \\
Subsection 6 (affected area after exiting SHC) & 5.72 & 5.1 & 18.18 \\
\hline
\end{tabular}

risk distribution of SHCs. Based on indirect index, such as operating speed and drivers' heart rate, and crashes distribution proportion of different positions in SHCs, driving risk distribution is theoretically analyzed. Driving risk affected areas on adjacent line units of SHCs are determined as $200 \mathrm{~m}$ sections before entering or after exiting SHCs. According to the changing regulations of drivers' heart rate and operating speed, driving risk distribution function can be described as cubic polynomial. Afterwards, the estimated parameters in cubic polynomial formula can be calibrated by survey crashes of SHCs, and then the expression of driving risk distribution function is finally established.

Contrasting to other research results, this one can reflect the influence of sharp horizontal curves to adjacent segments on segment dividing for crash prediction. It is recommended that, in addition to considerations on radius and crash rates, the influence of traffic and environments should be taken into account. The findings from this study can be applied to highway safety analysis and segment dividing of accident prediction.

\section{Conflict of Interests}

The authors declare that there is no conflict of interests regarding the publication of this paper.

\section{Acknowledgments}

This research was supported by the National Natural Science Foundation of China (no. 51408229, no. 51308059, no. 51278202, and no. 51378222), Key Laboratory of Road and Traffic Engineering of the Ministry of Education, Tongji University (no. K201204), Guangdong Communication Department (2013-02-068), and China Postdoctoral Science Foundation (2014M552399).

\section{References}

[1] G. Kanellaidis and S. Vardaki, "Highway geometric design from the perspective of recent safety developments," Journal of Transportation Engineering, vol. 137, no. 12, pp. 841-844, 2012.

[2] D. J. Findley, J. E. Hummer, W. Rasdorf, C. V. Zegeer, and T. J. Fowler, "Modeling the impact of spatial relationships on horizontal curve safety," Accident Analysis and Prevention, vol. 45, pp. 296-304, 2012.
[3] Transportation Bureau of Ministry of Public Security, Traffic Accidents Statistics Yearbook of People's Republic of China (20012012), China Communications Press, Beijing, China, 2012.

[4] Federal Highway Administration Synthesis of Safely Research Related to Speed and Speed Management .Publication No FHWA-RD-98-154.hlm.1999.

[5] F. Navin and K. Chow, Speed and the Probability of a Crash, Research Scientist Center for Transportation, 2001.

[6] R. Lamm, B. Psarianos, and T. Mailaender, Highway Design and Traffic Safety Engineering Handbook, McGraw-Hill, New York, NY, USA, 1999.

[7] S. Karen, P. T. McCoy, C. Pesti et al., "Relationship of design, operating and posted speed on horizontal curves on rural twolane highways in Nebraska," Transportation Research Record, 2002.

[8] R. A. Krammes, R. Q. Brackett, M. A. Shafer et al., "Horizontal alignment design consistency for rural two-lane highways," Tech. Rep. FHWA-RD-94-034, Federal Highway Administration, Washington, DC, USA, 1995.

[9] L. K. Fitzpatrick, L. Elefteriadou, R. Krammes et al., Speed Prediction for Two-Lane Rural Highways, Federal Highway Administration, Washington, DC, USA, 1999.

[10] X. Pan, H. Jiang, and Z. Yang, "Case study of accident black spot in mountain highway with small radius," Journal of Tongji University, vol. 35, no. 12, pp. 1642-1645, 2007.

[11] N. Shifeng, Research on traffic safety characteristics of curved section of highway [M.S. thesis], Jilin University, 2008.

[12] A. M. F. Medina and A. P. Tarko, "Speed changes in the vicinity of horizontal curves on two-lane rural roads," Journal of Transportation Engineering, vol. 133, no. 4, pp. 215-222, 2007.

[13] R. Yuanyuan, Research on driving dangerous area and driving behavior model in road curved section [Ph.D. thesis], Jilin University, 2011. 


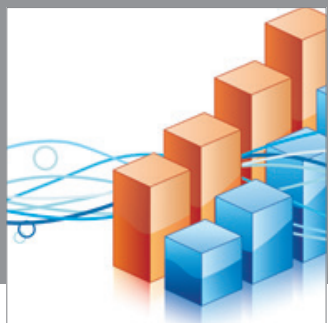

Advances in

Operations Research

mansans

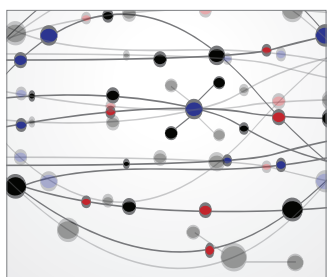

The Scientific World Journal
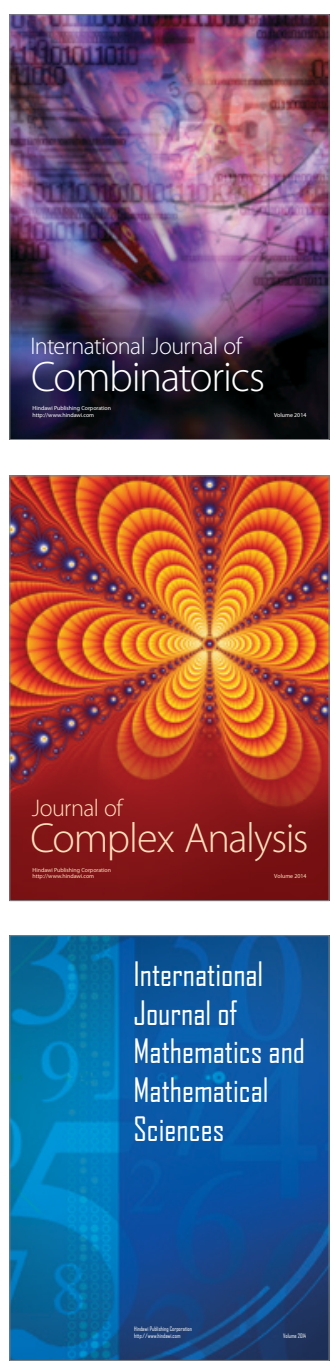
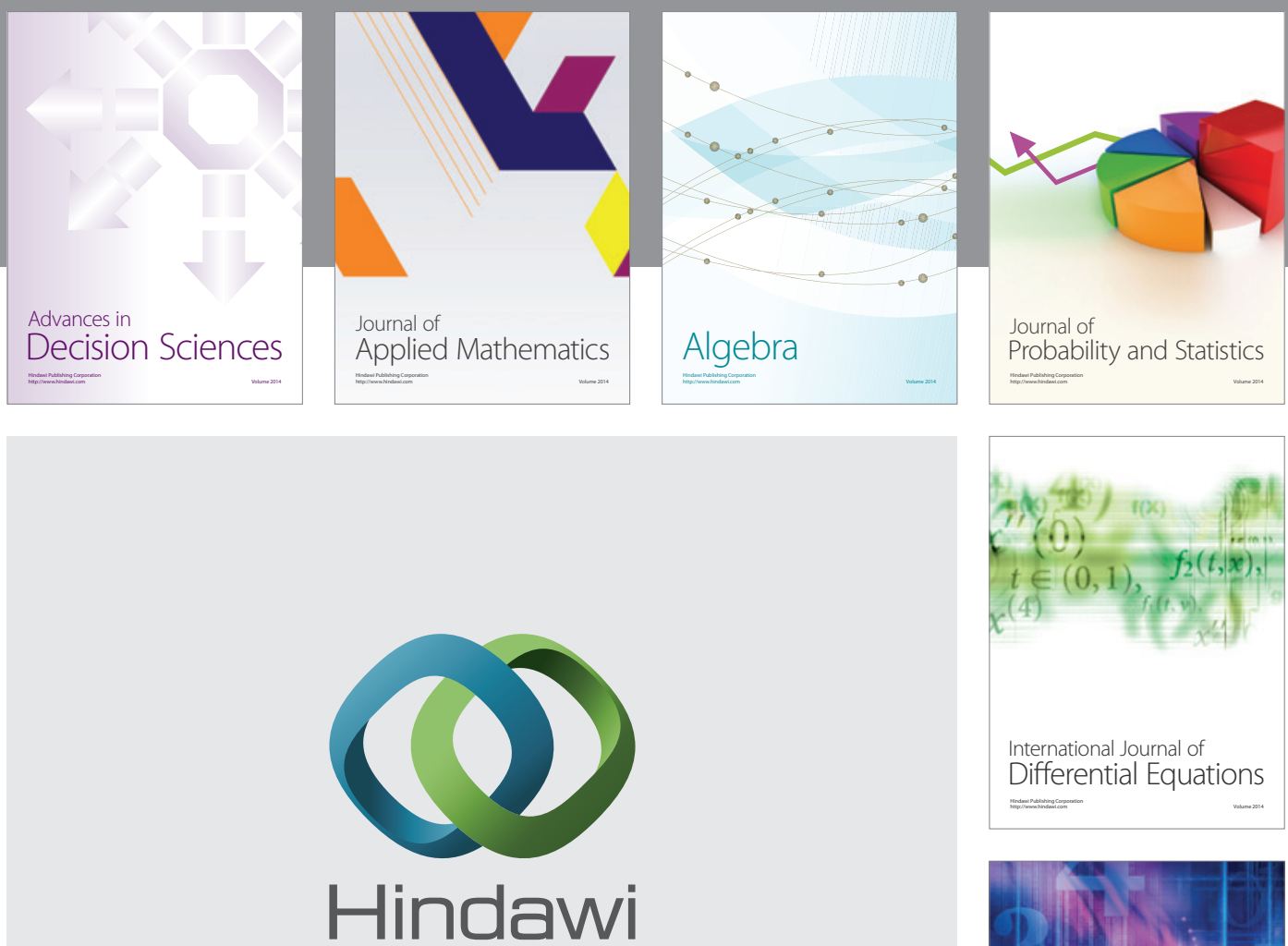

Submit your manuscripts at http://www.hindawi.com
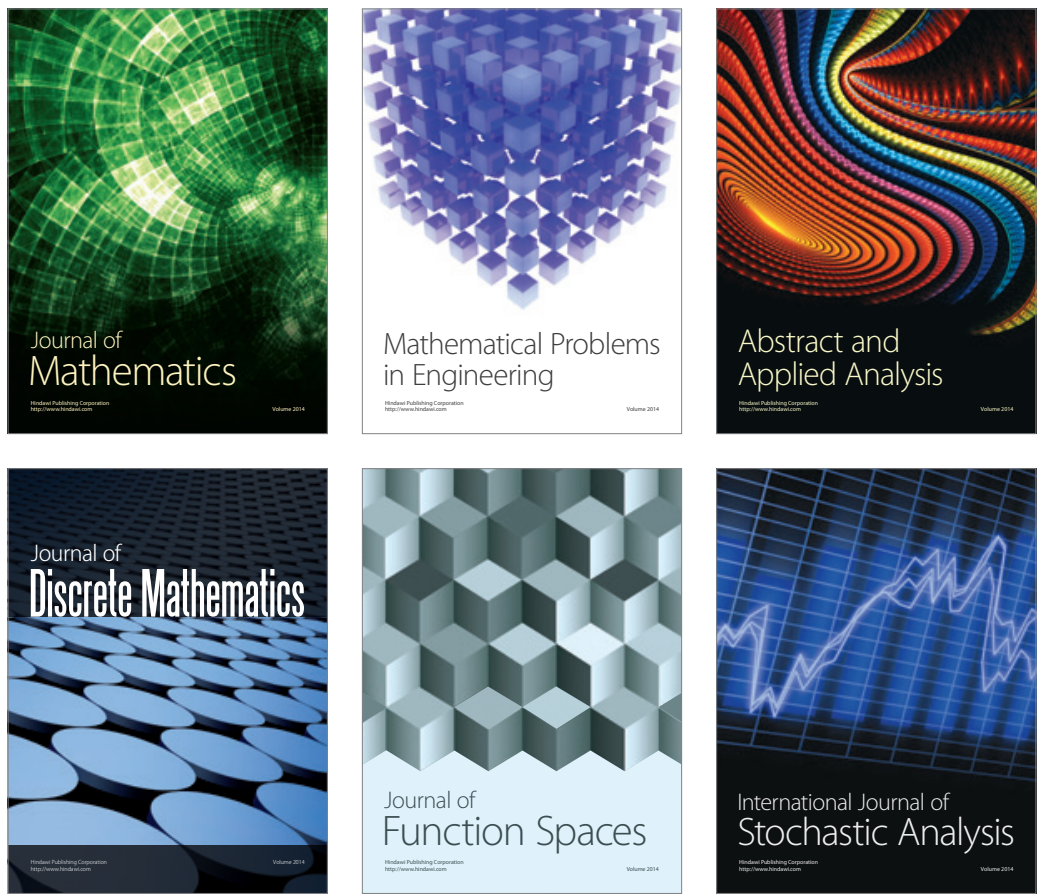

Journal of

Function Spaces

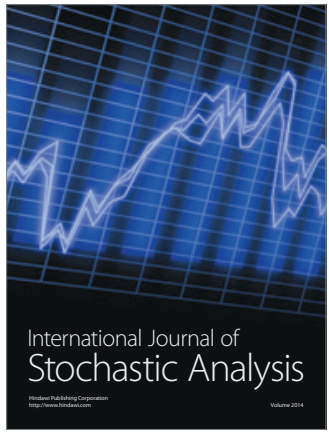

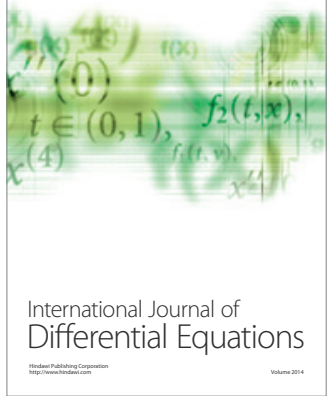
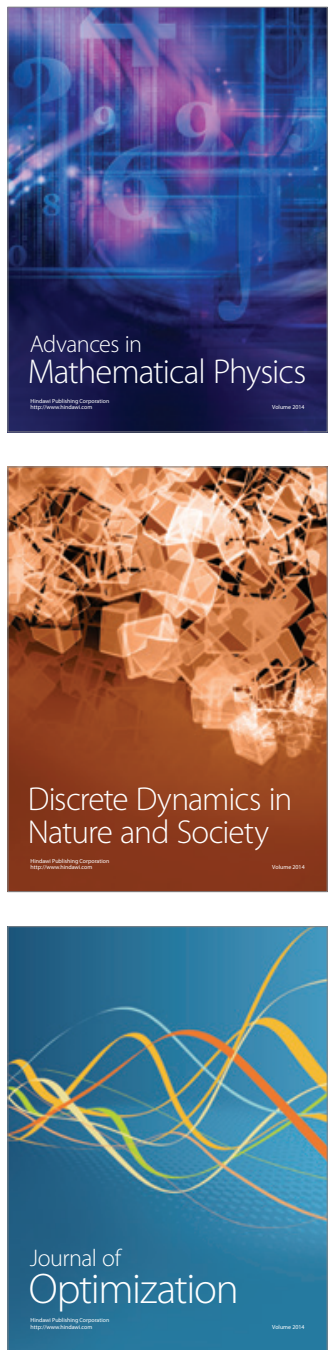